\title{
Exploring the College EFL Self-access Writing Mode Based on Automated Feedback
}

\author{
Sumin Wang ${ }^{1}$, Yizhong $\mathrm{Xu}^{1}$ \\ ${ }^{1}$ College of Foreign Languages, Nanjing University of Aeronautics and Astronautics, Nanjing, P.R. China \\ Correspondence: Sumin Wang, College of Foreign Languages, Nanjing University of Aeronautics and Astronautics, \\ Yudao Street 29, Qinhuai District, Nanjing, 210016, P.R. China.
}

Received: October 16, 2021

Accepted: November 21, 2021

Online Published: November 25, 2021

doi:10.11114/ijce.v5i1.5379

URL: https://doi.org/10.11114/ijce.v5i1.5379

\begin{abstract}
The present study is intended to construct a college EFL self-access writing mode based on automated feedback under the guidance of Formative Assessment Theory and Autonomous Learning Theory and attempts to apply it into college EFL teaching practice. Findings of this empirical-based study suggest that this self-access writing mode contributes to the enhancement of students' English writing competence, English writing motivation as well as their autonomy in self-revision.
\end{abstract}

Keywords: self-access writing mode, automated feedback, writing competence, writing motivation, self-revision

\section{Introduction}

With the increasing international communication and the growing demand for global academic exchange, it is becoming increasingly important in China to conduct written communication in English. The teaching of EFL writing is thus playing a significant role in the entire Chinese college EFL teaching system. In the traditional Chinese college-level EFL teaching mode, nevertheless, timely and efficient teachers' feedback is hardly guaranteed due to the large number of students and excessive workload of teachers. As a result, there has been little improvement in students' English writing competence and writing motivation. With massive application of information technology in Chinese university education, to integrate automatic feedback with teachers' feedback is undoubtedly an effective way to cope with the current challenge by reducing teachers' workload as well as enhancing students' self-access writing ability. The study of English writing feedback is accordingly gaining widespread concern in Chinese academia.

In recent years, automated feedback generated by AWE(Automated Writing Evaluation)is widely utilized in an attempt to enhance students' motivation and autonomy in EFL writing as well as their writing competence. Therefore, it is universally acknowledged to be an urgent mission to innovate a new teaching mode of EFL writing more appropriate to current Chinese college students by incorporating modern information technology into traditional teaching modes of EFL writing.

\section{Literature Review}

\subsection{Theoretical Framework}

Feedback has been a major concern in the field of EFL writing research since the 1990s. Systematic research has been conducted in terms of the efficacy of teachers' feedback as well as peers' feedback, which remains a controversial issue among researchers. Over the past decade, with the widespread use of computer and Internet technology in EFL teaching, automated feedback has emerged as a powerful compensation for the teaching of EFL writing. In recent years, the empirical studies of automated feedback have increased accordingly, many of which focused on its impact on enhancing students' EFL writing motivation, writing competence and writing strategies.

One important theoretical support for the utilization of automated feedback is the Formative Assessment theory. Formative assessment refers to the teaching procedure in which students' learning process is monitored and assessed together with timely feedback provided for teachers and students. As an important segment in formative assessment, timely feedback proves to be most helpful to students ( Gibbs\&Simpson, 2003)_because writing is a circular process of mental cognition, thinking, creation and social interaction( Krashen\&Terrel, 1983). Only through the process of modification, evaluation, feedback and re-modification will students' writing competence be genuinely improved. In 
Chinese EFL teaching, nevertheless, due to large-scale classes in college, timely feedback can be barely guaranteed until the emergence of the online automated feedback based on modern information technology. The other theoretical support is Autonomous Learning theory. Autonomous learning is first defined by Henry Holec(1981), who thought that autonomy was not an act, but a kind of ability which could be trained. Automated feedback helps to construct an optimal autonomous learning environment in which students can monitor, evaluate and modify their own writings independently by utilizing the automated evaluation, feedback and other online resources on an automated evaluation system.

\subsection{Previous Research on Automated Feedback}

Therefore, automated feedback has emerged as a heated issue in EFL teaching research, primarily focusing on the effect of automated feedback on learners' writing competence. Currently, a vast majority of studies both at home and abroad suggest that the effect of automated feedback mainly manifests itself in fostering students' writing motivation, improving their writing quality, facilitating their essay revision and so on ( Scharber \& Riedel, 2008; Chen \& Cheng, 2008;Tang \& Rich, 2011; Lv, 2015; Li, 2018). Some comparative studies demonstrate a noticeably better effect of combining automated feedback and teachers' feedback on boosting students' writing competence than mere automated feedback.(Grimes \& Warschauer, 2010; Sevcikova, 2018; Zhang, 2019). Notably, however, there are also some studies that have shown the limitations of automated feedback. For instance, there is much space for improvement in the evaluation of the content and thoughts of an essay $(\mathrm{Yu}, 2012)$ and it sometimes proves to be inaccurate to assess the inherent writing quality by automated feedback (Shi, 2012). According to previous studies, it is self-evident that there is a lack of further research on the teaching mode of EFL writing based on automated feedback.

Globally there are dozens of automated feedback systems in use, the most representative of which are EG(Project Essay Grade), IEA (Intelligent Essay Assessor) and E-rater. However, there are few systems targeted at Chinese EFL learners. In 2013, a website (www.pigai.org) was developed aiming to help improve Chinese EFL students' writing competence. This system is designed to generate an automated diagnostic feedback of students' essays from a total of 6 dimensions, including content, structure, sentence patterns, collocation, word choice and fluency. It is characterized by user-friendly, instant and sentence-by-sentence automated feedback along with learning tips and recommended expressions. Therefore, the present study is intended to construct a new teaching mode, namely, the self-access EFL writing mode based on automated feedback, aiming to increase students' writing competence and writing autonomy as well as to reduce teachers' workload,

\section{Research Design}

\subsection{Research Questions}

The present study is driven by the following questions:

(1) Is the self-access EFL writing mode helpful for students to improve their overall writing competence?

(2) Is the self-access EFL writing mode helpful for students to enhance their motivation to write and revise essays?

(3) Will the self-access EFL writing mode increase students' autonomy in writing particularly in terms of self-revision?

\subsection{Participants}

Participants of the present study are 139 non-English-major freshmen composed of four classes. They come from different parts of China with diversified cultural and major backgrounds as well as different English proficiency levels. In order to ensure the validity, students were not informed of the objectives of the teaching experiment. The experiment lasted 12 weeks, during which students were required to submit an essay on pigai website every four weeks and revise their writing before a certain deadline set by the instructor.

\subsection{The Design of Self-Access EFL Writing Mode Based on Automated Feedback}

In accordance with the objectives of Chinese college English teaching, the present study adopted a mixed-approach to automated feedback and teachers' feedback, in an attempt to construct a self-access EFL writing mode for students. The teaching mode is conducted using the following pattern:

(1) First of all, in order to better handle students' essays and collect data, teachers need to establish online classes and inform students to register and enroll in their own classes. Then teachers post a writing assignment through the pigai system and meanwhile specify the requirements and certain limitations in details, including the word count, the number of submissions, the deadline and so on. Finally, the students are informed of the precise number of the writing assignment in class.

(2) The second step is for students to submit their essays after accessing the website and completing the online 
writing assignment. Subsequently, students can revise their essays in accordance with the diagnostic feedback generated instantly by the system, including types of errors, methods of correction, learning tips, vocabulary expansion, recommended sentence patterns and so on. Students can repeatedly revise and resubmit their essays independently based on the automated feedback. Teachers can also specify the maximum numbers of submissions lest students revise their work too frequently.

(3) The last step is for teachers to provide comments and feedback. While students revise their writings independently, teachers can select some essays at random and provide individualized feedback. Then in class teachers need to point out common errors and problems in their writing summarized before class begins. More importantly, they should provide corrective feedback and guide students to make further revisions by integrating teachers' feedback and automated feedback. Meanwhile, it is essential for teachers to recommend online high-quality essays for all students to appreciate and learn from.

\subsection{Methods}

In order to examine the impact of the teaching mode on students' writing competence, quantitative and qualitative research methods were both employed for dimensional analysis. In the quantitative part, a writing pre-test and post-test were conducted with a time limit of 30 minutes respectively a week before the experimental teaching and a week afterwards. For the sake of reliability, two college EFL instructors were responsible for scoring their essays in accordance with Chinese CET-4 criteria, a nationwide English test for Chinese college students. The study adopted a contrastive quantitative analysis of students' scores by utilizing SPSS 19.0 software.

A questionnaire survey was administered to all participants after the experimental teaching was over. The aim is to explore students' writing motivation, their perceptions of self-access writing mode and their self-revision behavior. Following the questionnaire survey, an in-depth interview was also conducted with some participants selected at random in an attempt to discover how they perceived automated feedback and the self-access writing mode.

\section{Data Analysis and Results}

\subsection{Students' EFL Writing Competence}

Text quality is a direct criterion to measure students' EFL writing competence(Wang\&Zhang, 2012). In order to examine the impact of the new teaching mode on students' writing competence, SPSS 19.0 software is employed to compare and analyze their scores in both pretests and post-tests. In addition, paired samples $\mathrm{T}$ test is utilized to explore whether there are significant differences in their scores between the two tests.

Table 1. A comparison of average scores on two tests

\begin{tabular}{l|l|l|l|l}
\hline Indicator & Pretest & Post-test & T-value & Sig. \\
\hline $\begin{array}{l}\text { Relevance to the } \\
\text { topic(25\%) }\end{array}$ & 19.1 & 19.4 & -.480 & .637 \\
\hline $\begin{array}{l}\text { Flow of thoughts } \\
(25 \%)\end{array}$ & 21.6 & 22.5 & -1.522 & .145 \\
\hline Coherence(25\%) & 18.1 & 19.4 & -2.245 & .021 \\
\hline $\begin{array}{l}\text { Language } \\
\text { Accuracy(25\%) }\end{array}$ & 17.7 & 19.3 & -2.275 & .045 \\
\hline Total score (100) & 75.7 & 79.7 & -3.215 & .026 \\
\hline
\end{tabular}

The average scores in Table 1 are generated by the mean value of the scores provided by two instructors, including both total scores and sub scores, the division of which is consistent with the national CET-4 scoring criteria. As is illustrated in table 1, in comparison with the pretest, there is an increase to varied degrees in students' total scores as well as sub scores. Results of paired samples $T$ test indicate that in the first two criteria, namely, relevance to the topic and flow of thoughts, the difference between pretest and post-test is insignificant despite the increase of scores in the post-test. In contrast, there is a significant difference between the two tests in terms of coherence and accuracy as well as in total scores, which suggests that the self-access writing mode can contribute to the remarkable improvement of students' English writing competence.

\subsection{Students' EFL Writing Motivation}

In order to further explore the effect of the new writing mode, a questionnaire survey and an interview are conducted at the end of the experimental teaching. Results of both the questionnaire survey and the interview demonstrate the facilitating effect of the self-access writing mode on the enhancement of students' EFL writing motivation as well as their writing autonomy. 
$96.2 \%$ of all participants claimed that the self-access mode stimulated their interest in English writing and $86.9 \%$ of participants expressed their wish to continue to utilize the pigai system as a major platform combined with teachers' feedback to evaluate their writings. In terms of the reasons why they accept the new writing mode, $80.4 \&$ of participants choose the reason "Feedback is instant and time-saving", indicating the popularity of automated feedback. Students can receive both the instant automated feedback and regular teacher' feedback after completing their essays, which will stimulate their English writing motivation to write and revise their essays to the largest extent.

The results of the interview also indicate the positive impact of the self-access writing mode on students' writing motivation. Among 15 interviewees, 13 of them recognized automated feedback as the major feedback in their routine English writing practice, 11 of them claimed that the new mode stimulated their interest in the self-revision of their essays, and 10 of them agreed that automated feedback considerably reduced their anxiety about English writing.

\subsection{Students' Self-revision Autonomy of EFL Writing}

Statistics from the pigai system suggest that the average self-revision frequency of the first essay is 3.2 times, with $21.3 \%$ of participants having failed to do self-revision. The average self-revision frequency of the third essay slightly increased to 3.6 times, with the percentage of those who didn't do self-revision dropping to $16.4 \%$. Likewise, according to the questionnaire survey results, before using the pigai system, 36.5\% of participants never revised their essays independently and $42.9 \%$ of them never took the initiative to practise English writing without teachers' requirement. A series of data above have fully demonstrated the facilitating effect of the new writing mode on students' self-revision behavior. After incorporating automated feedback into their EFL writing process, there is a noticeable increase in the frequency of their self-revision, indicating their reinforced autonomy in revising their essays .

Nonetheless, the questionnaire survey also suggests that those who revise their essays less than 3 times account for $32.1 \%$ of all participants. Apparently, there is still a lack of motivation and initiative to utilize automated feedback among some participants, who tend to complete the required writing assignment passively. In addition, a vast majority of participants, accounting for $72 \%$ among all, are more concerned with grammatical and collocation errors rather than with those holistic problems in terms of content and coherence of the essay.

\section{Conclusion}

In the current information age, with the rapid development and popularization of information technology, it seems to be inevitable to incorporate an automated writing evaluation system into the teaching mode of college EFL writing. Findings of this study suggest that the self-access EFL writing mode based on automated feedback can compensate for the drawbacks of the traditional teaching mode of EFL writing. More importantly, it has proved to enhance students' English writing competence, writing motivation and self-revision autonomy, thus contributing to the improvement of overall teaching quality of EFL writing. In the future research of EFL writing, it will continue to be a major concern how to address the issue of integrating automated feedback with other types of feedback in order to create an optimal learning environment for students' self-access English writing.

\section{Acknowledgments}

The author is grateful to Nanjing University of Aeronautics and Astronautics for the financial support with grant number NR2019027. The study is also supported by the educational reform project of College of Foreign Languages Nanjing University of Aeronautics and Astronautics with grant number JY 12202004.

\section{References}

Chen, C. F. E., \& Cheng, W. Y. E. C. (2008). Beyond the design of automated writing evaluation:Pedagogical practices and perceived learning effectiveness in EFL writing classes. Language Learning Technology, 12(2), 94-112.

Gibbs, G., \& Simpson, C. (2004). "Does your assessment support your students' learning?" http://www.open.ac.uk/science/fdtl/documents/litreview.pdf(Nov.28)

Grimes, D., \& Warschauer, M. (2010). Utility in a Fallible Tool: A Multi-Site Case Study of Automated Writing Evaluation. Journal of Technology, Learning, and Assessment, 8(6), 4-43.

Holec, H. (1981). Autonomy and foreign language learning. Oxford : Pergamon Press.

Krashen, S. D., \& Terrel, T. D. (1983). The natural approach: Language acquisition in the classroom. Oxford : Pergamon Press.

Li, S. Y. (2018). Exploring EFL learners' self-access learning behavior and its efficacy in an intelligent evaluation environment. Technology Enhanced Foreign Language Education, 181(6), 47-52.

Lv, T. T., Zhang, H., \& Wang, N. (2015). A study on the effect of digitized writing system on students' writing competence. E-education Research. 266(6), 93-99. 
Scharber, C., Dexter, S., \& Riedel, E.(2008). Students' experiences with an automated essay scorer. The Journal of Technology, Learning and Assessment, 7(1), 1-44.

Sevcikova, B. W. (2018). Online open-Source writing aid as a pedagogical tool. English Language Teaching, 11(8), 126-142. https://doi.org/10.5539/elt.v11n8p126

Shi, X. L. (2012). Exploring the application of automatic evaluation system in the teaching practice of college EFL writing. Modern Education Technology, 22(10), 67-71.

Tang, J., \& Rich , C. (2011). Online Technology-Enhanced New Orleans: English Language Writing Assessment in the Chinese Classroom. Paper presented at 2011 Annual Conference of American Educational Research Association.

Yu, L., Qi, P., \& Guo, P. J. (2012). Investigating the impact of digitized writing system on the teaching of Chinese EFL writing. Technology Enhanced Foreign Language Education, 103(4), 17-21.

Zhang, H. (2019). A study of the effect of multi-feedback on the text quality of English writing. Technology Enhanced Foreign Language Education, 186(4), 34-39.

\section{Copyrights}

Copyright for this article is retained by the author(s), with first publication rights granted to the journal.

This is an open-access article distributed under the terms and conditions of the Creative Commons Attribution license which permits unrestricted use, distribution, and reproduction in any medium, provided the original work is properly cited. 